\title{
Factors Associated with Outcomes of Treatment among Pulmonary Tuberculosis Patients in Plateau State, Nigeria, 2011
}

Luka Mangveep Ibrahim ${ }^{1}$, Idris Suleiman Hadejia ${ }^{2}$, Patrick Nguku ${ }^{1}$, Gonen Mato Lakda ${ }^{1}$, Samuel Ogiri ${ }^{4}$ and Phillip Patrobas ${ }^{4}$

1. Department of Public Health, State Ministry of Health, Jos Plateau State 930222, Nigeria

2. Department of Community Medicine, Ahmadu Bello University, Zaria 810212, Nigeria

3. Nigeria Field Epidemiology and Laboratory Training Programme, Department of Public Health, Federal Ministry of Health, Abuja, Federal Capital Territory 900231, Nigeria

4. Tuberculosis Control Unit, ATM Cluster, World Health Organization, Abuja 900231, Nigeria

\begin{abstract}
SETTING: Plateau state is in north central Nigeria with population of 3.7 million people in 2011. Treatment of patient using the Directly Observed Treatment Short Course (DOTS) started since 2001. The cured rate had remained below expected target of $\geq$ 85\%. OBJECTIVE: To identify the factors associated with the outcomes of the treatment. DESIGN: We conducted a cross sectional study among pulmonary TB patients aged $\geq 15$ years. We reviewed their medical records, interviewed patients with structured questionnaires and conducted focus group discussions (FGD) about factors that affect TB treatment. Data were analyzed with epiInfo software. RESULTS: Of the 378 respondents, 178 (47\%) were smear positive. Cured, failure and default rates were 112 (62.8\%), 5 $(2.8 \%)$ and $5(2.8 \%)$, respectively. Knowledge of duration of treatment and previous medication for TB were associated higher (AOR: 9.62, 95\% CI: 2.28-40.68) and lower (AOR: 0.03, 95\% CI: 0.01-0.17) cured rates, respectively. FGD identified unfriendly attitude of health care workers, long distance and transport cost to health facility for DOT as the major barriers to treatment. CONCLUSION: Treatment interruption prevention, patients' education, decentralization of services to reduce distance and positive attitude of health care workers towards the patients will improve outcomes of treatment.
\end{abstract}

Key words: Treatment success, cured, default, failure, attitude.

\section{Introduction}

Tuberculosis (TB) is a major cause of mortality and morbidity in the world despite the availability of effective treatment for it more than half a century ago. It was responsible for the death of 1.5 million people in 2013 and the major cause of death among people living with HIV/AIDS [1]. Nigeria with an estimated incidence of 338/100,000 tops the TB burden countries in Africa [2]. The country adopted the WHO recommended Directly Observed Treatment Short Course (DOTS) for its control using the eight month strategy since 1996. Under the strategy, patients are

Corresponding author: Luka Mangveep Ibrahim, MPH, research field: public health. classified for treatment into two categories. Categories 1 patient are patients being treated under the strategy for the first time and categories 2 (retreatment) are patients with previous exposure to anti TB drugs [3]. The patients also have six mutually exclusive outcomes at the end of their treatment as follows: (1) cured, (2) treatment completed, (3) failure, (4) defaulted, (5) died, and (6) transferred out $[4,5]$. The expected outcome is a cured rate of at least $85 \%$ among the patients whose sputum tested positive for Mycobacterium tuberculosis at diagnosis. The sputum smear positive patients who fail to complete the eight month treatment and to achieve the cure are potential source of infection and multi-drug resistant TB (MDR-TB) which is an 
emerging of the TB control programme [6]. A national survey in Nigeria on MDR-TB in 2010, revealed prevalence rates of $2.9 \%$ among the new and $14.3 \%$ among retreatment TB cases [7].

In Plateau state Nigeria, TB control services using the WHO recommended DOTS strategy started in 2001 in five DOTS centers. Over the years, the state control programme embarked on expansion of the services such that by the end of 2010 there were 198 TB treatment (DOTS) centers [8]. Review of the performance Plateau state control programme for 2001-2010 revealed that of the 7,270 sputum smear positive patients registered for treatment only 5,282 (72.7\%) were cured or completed the eight month duration of treatment (treatment success) and 1,010 (14.1\%) either defaulted from or failed their treatment (Fig. 1) [9].

As a result of the low treatment success rates with corresponding high default and failure rates in the state, we conducted a study to identify the factors associated with the outcomes of the treatment to focus intervention on the poor outcomes in the state.

\section{Method}

\subsection{Study Setting}

Plateau state is one of the 36 states in the north central geopolitical zone of Nigeria. It had a population of 3.7 million people in 2011. We conducted a cross-sectional study between June and July 2011 among Pulmonary TB patients aged 15 years and above diagnosed by sputum acid fast bacilli (AFB) microscopy, chest X-ray or by a clinician, and were in their eight months of treatment at the time of the study. We excluded children ( $<15$ years) in the study because parents or care givers might be required to give information.

We defined outcomes of TB treatment using the WHO standard definition as follows: (1) cured, refers to a patient who was initially smear positive at start of treatment, has completed the full course of the treatment and has remained smear negative at the end of the seventh month and on at least one other occasion; (2) treatment completed, is a patient who completes the full course of anti-TB treatment but does not meet the

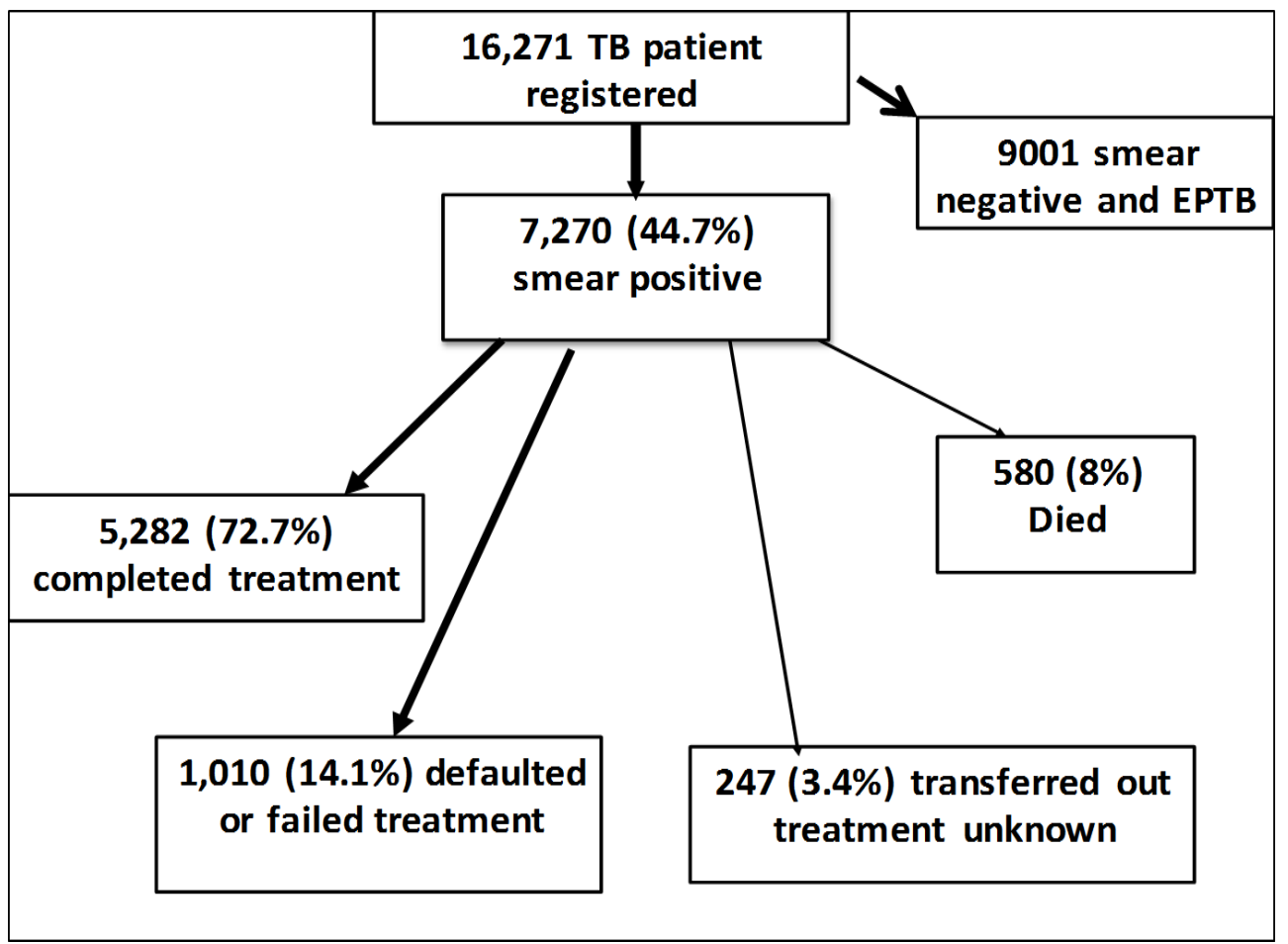

Fig. 1 Outcomes of pulmonary smear positive TB patients in Plateau state 2001-2010. 
condition of cured. This definition applies to both sputum smear positive and negative TB patients; (3) failure, refers to a patient who still remains sputum smear positive at end of fifth or seventh month of treatment; and (4) defaulted, applies to a patient whose treatment was interrupted for at least 2 months. Patients who died or were transferred out were excluded from the study.

\subsection{Sample Size Determination, Data Collection and Analysis}

We used the highest cure rate of $63.5 \%$ achieved in the state in 2006 to calculate the minimum sample size. Using a power of $80 \%, 95 \%$ confidence interval, degree of precision of 0.05 and making provision for $10 \%$ non-responses gave us a sample size of 392 [10].

We used the TB central register that contained patients' names and addresses to determine the sampling frame. Of the 798 eligible patients, 392 were selected by systematic random sampling. We extracted clinical and demographic data from the patients' medical records. They were traced and interviewed using an interviewer administered structured questionnaire on their social, economic, and behavioral characteristics including knowledge on treatment duration, and factors associated with outcome of treatment. Information on the distance of the patients' place of abode to the health facilities was measured by the mileage of the vehicles (motorbikes or car) that we used to trace the patients.

We conducted focus group discussions (FGDs) with homogeneous (males and females) groups of the selected patients on factors that affect adherence of TB treatment using a pre-designed FGD guide.

We entered the data into an Epi info version 3.3.2 database and performed descriptive, bivariate, and multivariate analysis using odds ratio and 95\% confidence interval to determine association between categorical variables. The qualitative data from the FGDs were transcribed into written form, translated from the local language to English and analyzed according to the specific thematic areas.

\subsection{Ethical Considerations}

We obtained ethical clearance for the study from the Plateau state ethical review committee. Informed consent was also obtained from all respondents involved in the study.

\section{Results}

A total of 378 (96.4\%) of the 392 selected patients were traced and interviewed with mean age was $37.6 \pm$ 13.5 (females: 38.5, male: 35.8) years, 60.6\% (229) were male and $47 \%$ (178) were sputum smear positive. Majority (61\%) were 25-44 years (Table 1), 72\% (272) were married, $18.5 \%$ (70) gave history of cigarette smoking, 44\% (167) had history of alcohol use, and 19\% (72) lived more than $5 \mathrm{~km}$ from their TB treatment sites (Table 2). Furthermore, 15.3\% (58) did not know the duration for the TB treatment. The overall treatment success was $95.8 \%$ (smear negative: $97.0 \%$, smear positive: $94.4 \%$ ) and $2.9 \%$ (11) defaulted from treatment. Among the smear positive patients, 63\% (112) were cured, $3 \%$ (5) failed their treatment and 3\% (5) defaulted from treatment.

The bivariate analysis (Table 3 ) showed that being consistent on treatment (OR: 2.80; 95\% confidence interval (CI): 1.38-5.56) and having knowledge of the duration of TB treatment (OR: 3.83; 95\% CI: 1.64-8.91) were significantly associated with high cured rates among smear positive TB patients. Poor outcomes or lower cured rates was more likely among patients with previous exposure to anti TB treatment (OR: 0.16; $95 \%$ CI: 0.06-0.41). The multivariate analysis, after controlling for other factors showed that patients' knowledge of the duration for TB treatment (adjusted odds ratio $=(\mathrm{AOR}): 9.62 ; 95 \% \mathrm{CI}: 2.28-40.68)$ and previous exposure to anti TB treatment (AOR: 0.03, 95\% CI: 0.01-0.17) remained independent determinants for cure from TB among the smear positive TB patients (Table 3).

TB patients who participated in the FGDs noted that 
Table 1 Age and sex distribution of Pulmonary TB patients.

\begin{tabular}{llll}
\hline \multirow{2}{*}{ Age group in years } & \multicolumn{2}{c}{ Sex } & Total \\
\cline { 2 - 4 } & $\begin{array}{l}\text { Female } \\
\text { Frequency }(\%)\end{array}$ & $\begin{array}{l}\text { Male } \\
\text { Frequency }(\%)\end{array}$ & Frequency $(\%)$ \\
\hline $15-19$ & $2(1.3)$ & $10(4.4)$ & $12(3.2)$ \\
$20-24$ & $19(12.8)$ & $17(7.4)$ & $36(9.5)$ \\
$25-29$ & $28(18.8)$ & $32(14.0)$ & $60(15.9)$ \\
$30-34$ & $32(21.5)$ & $45(19.7)$ & $77(20.4)$ \\
$34-39$ & $18(12.1)$ & $31(13.5)$ & $49(13.0)$ \\
$40-44$ & $21(14.1)$ & $23(10.0)$ & $44(11.6)$ \\
$44-49$ & $6(4.0)$ & $20(8.7)$ & $26(6.9)$ \\
$50-54$ & $7(4.7)$ & $20(8.7)$ & $27(7.1)$ \\
$>54$ & $16(10.7)$ & $31(13.5)$ & $47(12.4)$ \\
Total & $149(39.4)$ & $229(60.6)$ & $378(100)$ \\
\hline
\end{tabular}

Table 2 Distribution of clinical and social characteristics of respondents $(n=378)$.

\begin{tabular}{|c|c|c|c|c|}
\hline Characteristics of patients & & $\begin{array}{l}\text { Sputum smear } \\
\text { negative }\end{array}$ & $\begin{array}{l}\text { Sputum smear } \\
\text { positive }\end{array}$ & Total $(\%)$ \\
\hline \multirow{4}{*}{ Marital status } & Single & $38(46.9)$ & $43(53.1)$ & $81(21.4)$ \\
\hline & Married & $151(55.7)$ & $120(44.3)$ & $271(71.7)$ \\
\hline & Separated or Divorced & $8(45.5)$ & $13(54.5)$ & $21(5.6)$ \\
\hline & Widow & $3(60.0)$ & $2(40.0)$ & $5(1.3)$ \\
\hline \multirow{6}{*}{ Occupation } & Farming & $79(59.0)$ & $55(41.0)$ & $134(35.4)$ \\
\hline & Schooling & $16(42.1)$ & $22(57.9)$ & $38(10.1)$ \\
\hline & Applicant & $21(46.7)$ & $24(53.3)$ & $45(11.9)$ \\
\hline & Civil servant & $30(56.2)$ & $28(43.8)$ & $58(15.3)$ \\
\hline & Business & $42(56.0)$ & $33(44.0)$ & $75(19.8)$ \\
\hline & Others & $6(27.3)$ & $16(72.7)$ & $22(5.8)$ \\
\hline \multirow{5}{*}{ Education level } & None & $39(56.5)$ & $30(43.5)$ & $69(18.3)$ \\
\hline & Qur'anic & $13(48.1)$ & $14(51.9)$ & $27(7.1)$ \\
\hline & Primary & $48(52.2)$ & $44(47.8)$ & $92(24.3)$ \\
\hline & Secondary & $60(49.6)$ & $61(50.4)$ & $121(32.0)$ \\
\hline & Tertiary & $39(57.4)$ & $29(42.6)$ & $68(18.0)$ \\
\hline \multirow{4}{*}{ Role in family } & Main Bread winner & $96(53.3)$ & $84(46.7)$ & $180(47.6)$ \\
\hline & Supports family & $22(37.9)$ & $36(62.1)$ & $58(15.3)$ \\
\hline & Dependant & $30(50.0)$ & $30(50.0)$ & $60(15.9)$ \\
\hline & House wife & $52(65.0)$ & $28(35,0)$ & $80(21.2)$ \\
\hline \multirow{3}{*}{ HIV status } & HIV positive & $59(69.4)$ & $26(30.6)$ & $85(22.5)$ \\
\hline & HIV Negative & $71(44.1)$ & $90(55.9)$ & $161(42.6)$ \\
\hline & HIV status unknown & $70(53.0)$ & $62(47.0)$ & $132(34.9)$ \\
\hline \multirow{2}{*}{ Interrupted treatment } & Yes & $28(39.4)$ & $43(60.6)$ & $71(18.8)$ \\
\hline & No & $172(56.0)$ & $135(44.0)$ & $307(81.2)$ \\
\hline \multirow{2}{*}{ Smoke cigarette } & Yes & $33(47.1)$ & $37(52.9)$ & $70(18.5)$ \\
\hline & No & $167(54.2)$ & $141(45.8)$ & $308(81.5)$ \\
\hline \multirow{2}{*}{ Use alcohol } & Yes & $92(55.1)$ & $75(44.9)$ & $167(44.2)$ \\
\hline & No & $108(51.2)$ & $103(48.8)$ & $211(55.8)$ \\
\hline \multirow{2}{*}{ Knew duration of TB treatment } & Yes & $156(53.2)$ & $137(46.8)$ & $293(77.5)$ \\
\hline & No & $44(51.8)$ & $41(48.2)$ & $85(22.5)$ \\
\hline
\end{tabular}


Table 3 Factors associated with cured among smear positive TB patients $(n=178)$.

\begin{tabular}{|c|c|c|c|c|}
\hline \multirow{2}{*}{ Characteristics } & \multicolumn{2}{|c|}{ Cured } & \multirow{2}{*}{$\begin{array}{l}\text { Crude Odd Ratios } \\
(95 \% \mathrm{CI})\end{array}$} & \multirow{2}{*}{$\begin{array}{l}\text { Adjusted Odd Ratios } \\
(95 \% \mathrm{CI})\end{array}$} \\
\hline & Yes & No & & \\
\hline Marital status (Married) & 73 & 47 & $0.76(0.39-1.46)$ & $0.25(0.18-2.48)$ \\
\hline Sex (male) & 73 & 43 & $1.00(0.53-1.90)$ & $1.76(0.40-7.81)$ \\
\hline HIV negative $(n=116)$ & 59 & 31 & $1.01(0.55-1.87)$ & $0.67(0.18-2.48)$ \\
\hline Main bread winner of the family & 53 & 31 & $1.04(0.55-1.87)$ & $2.85(0.53-15.21)$ \\
\hline Does not smoke cigarette & 89 & 52 & $1.04(0.50-2.20)$ & $2.25(0.54-9.42)$ \\
\hline Distance $<5 \mathrm{~km}$ from treatment site & 95 & 52 & $1.04(0.69-3.30)$ & $0.90(0.21-3.80)$ \\
\hline No formal education & 30 & 14 & $1.36(0.66-2.80)$ & $1.79(0.50-6.42)$ \\
\hline Self employed & 61 & 41 & $0.76(0.41-1.41)$ & $0.85(0.28-2.55)$ \\
\hline Does not take alcohol & 69 & 34 & $1.51(0.82-2.79)$ & $2.28(0.69-7.45)$ \\
\hline Consistent on treatment & 94 & 42 & $2.80(1.38-5.56)$ & $3.51(0.92-13.29)$ \\
\hline Knew duration of $\mathrm{TB}$ treatment & 102 & 48 & $3.83(1.64-8.91)$ & $9.62(2.28-40.68)$ \\
\hline Previous exposure to anti TB drugs & 7 & 19 & $0.16(0.06-0.41)$ & $0.03(0.01-0.17)$ \\
\hline
\end{tabular}

the drugs had given them relief from their disease but were unpleasant to take. A male patient said "I did not find it easy with the drugs, they are too big. I got tired of the drugs and wished to stop the treatment. There was a time I could perceive the unpleasant taste of the drug in my mouth".

They also noted that the daily observation of treatment (DOT) at the health facility and cost of transportation to the clinic for DOT by the health care worker made the treatment too cumbersome to them and might contribute to non adherence to the treatment. A female participant said "I had complained a lot about the daily treatment in the hospital, sometimes I would like to travel for a week or two but I cannot because I do not want to miss my treatment", another male participant said "When you go to the hospital, you are expected to swallow the drug in the hospital but the health care worker will not give you water to swallow the drugs. I can't imagine going about with water in bottle or sachet in my pocket every day because I am on TB treatment".

They identified unfriendly attitude of the health care workers towards them as the major factor responsible for non-adherence to treatment contributing to poor outcome. A male participant said "The health workers should have good attitude towards us, they cause us more problems when they are harsh to us".

\section{Discussion}

Our study showed that previous exposure to anti TB treatment, knowledge of the duration of the duration of treatment and attitude of health care workers towards the patients are the important factors associated with outcome of treatment among pulmonary TB patients in Plateau state. The main goal of TB control is to achieve high cured among the smear positive TB patient especially when treated in the first instance. According to the WHO indicators for Programme Outcomes, retreatment or patients with previous exposure to anti TB drugs is indication of ineffective treatment, incorrect administration of medication or non adherence to the direct observation of treatment (DOT) either on the part of the patient or the service providers [11]. Studies have shown that people who had history of failing to adhere to treatment in the first instance are more likely to fail subsequent treatments since the first failure might had been due to unresolved cause of poor compliance to treatment of drug resistance. Previous exposure to anti-TB medicated especially taking medication outside the national TB control programme had been reported to lead to poor outcomes of treatment $[12,13]$. These are indicative of likely doubt of adherence to DOT protocol if they were treated under the national control programme because quality assured drugs is one of the major components 
of the DOTS strategy. TB treatment takes a long duration; knowledge of the long duration is key determinant factor for successful treatment. Additionally, the disappearance of symptoms is an indicator of clinical improvement from diseases and a measure of the effectiveness of the therapy. It is common place for symptoms of TB to disappear even within a few weeks of treatment due to the quality of the drug and implementation of DOT. TB Patients with inadequate knowledge of the duration of the treatment and the need to continue the treatment for the right duration even when symptoms disappear may feel that they are cured and thus stop the treatment. Study in Cameroun showed that defaults among patient were highest in the continuation phase of treatment corresponding to the time of improvement of the signs and symptoms of the disease [14]. Studies in India, Zambia, Ethiopia and Nigeria also corroborate our findings on the relationship between patients' knowledge on the duration of treatment and the outcome of the treatment [15-18]. Patients' knowledge on duration of treatment underscores the importance of patients' education which also has bearing on the skills of the health workers and patient-service providers' relationship. The patients' knowledge depends on the information passed to them and the quality of communication between patient and the health care workers [19, 20]. These also depend on the communication skills of the health care workers and their attitude towards the patient. Patients who have confidence in the health care worker are more likely to follow their instructions and adhere to treatment duration. Conversely, patients who feel threatened, not loved or respected by the health care workers may choose not to continue their treatment leading to failure or default from the treatment. O'Boyle et al. reported that patient who feels they are not treated with respect and empathy may not complete their treatment [21]. In the same vein, Jaiswal et al. also noted that reasons for patient defaulting from treatment in a study in India was blamed on the health workers for their untoward behavior and attitude toward them whom they described as rude and unhelpful [22]. These findings are supported by the views of the participants at the focus group discussions in our study.

We also explored the demographic and behavioral characteristics of the patient that influenced the outcome of treatment among TB patients. Studies have shown that these factors affect the outcomes of TB treatments. Karim et al. in Bangladesh and Salami and Olubayo in Ilorin Nigeria reported that male were less likely to adhere to treatment leading to poorer outcomes [23, 24]. Similarly, the study of WU et al. in Taiwan and a case control study in China by Ai et al. revealed that elderly patients and those above 60 years had poorer treatment outcomes respectively [25, 26]. These findings were in contrast to our finding which showed that the sex and age of the patients were not significantly associated with the outcome of treatment. Alcohol consumption and cigarette smoking are behavioral factors with significant effects on outcomes of TB treatment. Those who consume alcohol may tend to forget to take their drugs leading to default. Alcohol also alters the individual immune system contributing to failure of the treatment. Studies from Uzbekistan [27] and Bangalore city [28] noted that alcoholics were more likely to default from their treatment. Their finding is not in congruent with our results despite the high proportion (44\%) of respondents who reported taking alcohol. Similarly, our study did not show association between poor outcomes with cigarette smoking. Cigarette smoke is known to damage the lungs and suppresses the individual adaptive immune responses affecting patients' response to TB treatment [29]. Our findings is supported by Tachfouti et al. in their study in Morocco [30] and Santa et al. in India who reported that cigarette smokers had poorer TB treatment than non smoker [31].

Our study had the following limitations; firstly we were not able to trace all the respondents (patients) eligible for the study due to incorrect or untraceable addresses. Secondly the data we gathered on smoking 
and alcohol consumption were based on self-information and might be subject to bias because it is possible for some patient to conceal the information. Thirdly we did not explore other behavioral factors like substance abuse such as hard drugs that might be associated with cigarette smoking and alcohol consumption with potential negative effect on outcomes of TB treatment.

\section{Conclusion}

Our study showed that previous exposure to anti TB treatment, knowledge of the duration of treatment, attitude of health care workers towards the patients are the important factors associated with outcome of the TB treatment Plateau state.

\section{Recommendations}

The plateau state TB control programme should train all health workers involved in management of patients on patients education on the duration of treatment and the need to continue treatment for the prescribed duration even if symptoms disappear completely.

The National TB control programme should train all TB focal persons on inter-personal communications to relate and treat patients with empathy and respect to ensure adherence to treatment.

\section{Acknowledgement}

We want to acknowledge the staff of the Plateau state TB and leprosy control programme for their support during the cause of acquisition of the data for the study.

\section{Authors' Contributions}

Luka Mangveep Ibrahim: Conception, design, writing of protocol for the study, acquisition of data, analysis, interpretation and wrote the manuscript. Idris Suleiman Hadejia: Design and writing of protocol for the study, analysis and interpretation of the data. Patrick Nguku, Samuel Ogiri, Phillip Patrobas and Gonen Mato Lakda: Revised the manuscript critically for intellectual content and approved the final manuscript.

\section{References}

[1] World Health Organization. 2014. "Global tuberculosis report 2014.” WHO/HTM/TB/2014.08 Accessed June 30, 2015.

http://www.who.int/tb/publications/global_report/gtbr14_ main_text.pdf.

[2] Federal Ministry of Health Nigeria. 2012. "Report: First National TB Prevalence Survey 2012, Nigeria.” Federal Ministry of Health Nigeria. Accessed July 15, 2015. http://www.who.int/tb/publications/NigeriaReport_WEB _NEW.pdf.

[3] Federal Ministry of Health Nigeria. 2008. "National TB and Leprosy Control Programme Workers Manual; 2008." Federal Ministry of Health. Nigeria.

[4] World Health Organization 2006. "Revised TB Recording and Reporting Forms and Registers-Version 2006. Geneva, World Health Organization, 2006." WHO/HTM/TB/2006.373. Accessed August 28, 2014. http://www.who.int/tb/dots/r_and_r_forms/en/.

[5] World Health Organization. 2006. "The Stop TB Strategy: Building on and Enhancing DOTS to Meet the TB-Related Millennium Development Goals. Geneva.” World Health Organization. 2006 WHO/HTM/TB/2006.368. Accessed August 28, 2014. http://www.who.int/tb/publications/2006/who_htm_tb_20 06_368.pdf.

[6] World Health Organization. 2007. "The Global MDR-TB and XDR-TB Response Plan, 2007-2008." WHO/HTM/TB/2007.387. Accessed 28, 2014. http://www.who.int/tb/publications/2007/global_response _plan.pdf.

[7] Plateau State Ministry of Health. 2004. "Plateau State TB and Leprosy Control Programme, Fourth Quarter Report, January 2009.” Plateau State Ministry of Health, Nigeria.

[8] Plateau State Ministry of Health. 2011. "Plateau State TB and Leprosy Control Programme, Annual Report, 2011." Plateau State Ministry of Health, Nigeria.

[9] Daniel, W. W. 2009. Biostatistics: A Foundation for Analysis in the Health Sciences. 9th ed., Georgia State University: John Wiley \& Sons Inc., 192-3.

[10] World Health Organization. 2004. "Indicators for Program Outcomes. Compendium of Indicators for Monitoring and Evaluating National Tuberculosis Programs." World Health Orgnazation2004. Accessed June 28, 2015. http://apps.who.int/iris/bitstream/10665/68768/1/WHO_ HTM_TB_2004.344.pdf. 


\section{Tuberculosis Patients in Plateau State, Nigeria, 2011}

[11] Babalık, A., Kılıcaslan, Z., Kızıltaş, Ş., Gencer, S., and Ongen, G. 2013. "A Retrospective Case-Control Study, Factors Affecting Treatment Outcomes for Pulmonary Tuberculosis in İstanbul, Turkey." Balkan Med. J. 30 (2): 204-10.

[12] Jha, U. M., Satyanarayana, S., Dewan, P. K., Chadha, S., Wares, F., Sahu, S., Gupta, D., and Chauhan, L. S. 2010. "Risk Factors for Treatment Default among re-Treatment Tuberculosis Patients in India, 2006." PLOS ONE 5 (1): e8873.

[13] Gupta, S., Gupta S and Behera D. 2011. "Reasons for Interruption of anti-Tubercular Treatment as Reported by Patients with Tuberculosis Admitted in a Tertiary Care Institute." Indian J. Tuberc. 58 (1): 11-7.

[14] Pefura Yone E. W, Kengne A. P, Kuaban C. 2011. "Incidence, Time and Determinants of Tuberculosis Treatment Default in Yaoundé, Cameroon: A Retrospective Hospital Register-Based Cohort Study." BMJ Open 1: e000289.

[15] Kaona, F. A. D., Tuba, M., Siziya, S., and Sikaona, L. 2004. "An Assessment of Factors Contributing to Treatment Adherence and Knowledge of TB Transmission among Patients on TB Treatment." BMC Public Health 4: 68.

[16] Tekle, B., Mariam, D. H., and Ali, A. 2002. "Defaulting from DOTS and Its Determinants in Three Districts of Arsi Zone in Ethiopia." Int. J. Tuberc. Lung Dis. 6 (7): 573-9

[17] Fatiregun, A. A., Ojo, A. S., and Bamgboye, A. E. 2009. "Treatment Outcomes among Pulmonary Tuberculosis Patients at Treatment Centers in Ibadan, Nigeria." Annals of African Medicine 8 (2): 100-4.

[18] Comolet, T. M, Rakotomalala, R., and Rajaonarioa, H. 1998. "Factors Determining Compliance with Tuberculosis Treatment in an Urban Environment, Tamatave, Madagascar." Int. J. Tuberc. Lung Dis. 2 (11): 891-7.

[19] Mesfin, M. M., Newell, J. N., Walley, J. D., Gessessew, A., Tesfaye, T., Lemma, F., and Madeley, R. J. 2009. "Quality of Tuberculosis Care and Its Association with Patient Adherence to Treatment in Eight Ethiopian Districts." Health Policy and Planning 24 (6): 457-66.

[20] O’Boyle, S. J. O., Power, J. J., Ibrahim, M. Y., and Watson, J. P. 2002. "Factors Affecting Patient Compliance with anti-Tuberculosis Chemotherapy Using the Directly Observed Treatment, Short-Course Strategy (DOTS).” Int. J. Tuberc. Lung Dis. 6 (4): 307-12.

[21] Jaiswal, A., Singh, V., Ogden, J. A., Porter, J. D. Sharma,
P. P., Sarin, R., Arora, V. K., and Jain, R. C. 2003. "Adherence to Tuberculosis Treatment: Lesson from the Urban Setting of Delhi, India." Tropical Medicine and International Health 8 (7): 625-33.

[22] Karima, F., Ahmed, F., Begun, I., Johnson, E., and Diwan, V. K. 2008. "Female-Male Differences at Various Clinical Step of TB Treatment." Int. J. Tuberc. Lung Dis. 12 (11): 1336-9.

[23] Salami, A. K., and Olubayo, P. O. 2003. "Management Outcome of Pulmonary Tuberculosis: A Nine Year Review in Ilorin." West Afr. J. Med. 22 (2): 114-5.

[24] Wu, P., Chou, P., Chang, N., Sun, W., and Kuo, H. 2009. "Assessment of Changes in Knowledge and Stigmatization Following Tuberculosis Training Workshops in Taiwan.” J. Formos. Med. Assoc. 108 (5): 349-435.

[25] Ai, X., Men, K., Guo, L., Zhang, T., Zhao, Y., Sun, X., Zhang, H., He, G., van der Werf, M. J., and van den Hof, S. 2010. "Factors Associated with Low Cure Rate of Tuberculosis in Remote Poor Areas of Shaanxi Province, China: A Case Control Study." BMC Public Health 10: 112.

[26] Hasker, E., Khodjikhanov, M., Usarova, S., Asamidinov, U., Yuldashova, U., van der Werf, M. J., Uzakova, G., and Veen, J. 2008. "Default from Tuberculosis Treatment in Tashkent, Uzbekistan; Who Are These Defaulters and Why Do They default?" BMC Infect. Dis. 8: 97.

[27] Vijay, S., Balasangameswara, V. H., Jagannatha, P. S., Saroja, V. N., and Kumar, P. 2003. "Defaults among Tuberculosis Patients Treated under DOTS in Bangalore City: A Search for Solution.” Ind. J. Tub. 50: 185.

[28] Schneider, N. K., and Novotny, T. E. 2007. "Addressing Smoking Cessation in Tuberculosis Control." Bull World Health Organ 85 (8): 647-8.

[29] Tachfouti, N., Nejjari, C., Benjelloun, M. C., Berraho, M., Elfakir, S., El Rhazi, K., and Slama, K. 2011. "Association between Smoking Status, Other Factors and Tuberculosis Treatment Failure in Morocco." Int. J. Tuberc. Lung Dis. 15 (6): 836-43.

[30] Santha, T., Garg, R., Frieden, T. R., Chandrasekaran, V., Subramani, R., Gopi, P. G., Selvakumar, N., Ganapathy, S., Charles, N., Rajamma, J., and Narayanan, P. R. 2002 "Risk Factors Associated with Default, Failure and Death among Tuberculosis Patients Treated in a DOTS Programme in Tiruvallur District, South India, 2000." Int. J. Tuberc. Lung Dis. 6 (9): 780-8. 